\title{
The Polish Prevalence of Infection in Intensive Care (PPIC): A one-day point prevalence multicenter study
}

\author{
Dariusz Tomaszewski ${ }^{1}, A-F$, Zbigniew Rybicki ${ }^{1, A-C, E, F}$, Wiesława Duszyńska ${ }^{2, C, D, F}$ \\ ${ }^{1}$ Department of Anesthesiology and Intensive Therapy, Military Institute of Medicine, Warszawa, Poland \\ ${ }^{2}$ Department of Anesthesiology and Intensive Care, Wrocław University Hospital, Poland \\ A - research concept and design; $\mathrm{B}$ - collection and/or assembly of data; $\mathrm{C}$ - data analysis and interpretation; \\ $D$ - writing the article; $E$ - critical revision of the article; $F$ - final approval of the article
}

\section{Address for correspondence}

Wiesława Duszyńska

E-mail:w.duszynska@wp.pl

\section{Funding sources}

None declared

\section{Conflict of interest}

None declared

\section{Acknowledgements}

The authors are grateful to all the doctors who collected data and submitted questionnaires, and to Łukasz Strużecki for his help with this study.

Received on December 5, 2017

Reviewed on April 16, 2018

Accepted on August 9, 2018

Published online on April 13, 2019

Cite as

Tomaszewski D, Rybicki Z, Duszyńska W. The Polish

Prevalence of Infection in Intensive (are (PPIC): A one-day

point prevalence multicenter study. Adv Clin Exp Med.

2019;28(7):907-912. doi:10.17219/acem/94147

DOI

10.17219/acem/94147

\section{Copyright}

Copyright by Author(s)

This is an article distributed under the terms of the

Creative Commons Attribution Non-Commercial License

(http://creativecommons.org/licenses/by-nc-nd/4.0/)

\begin{abstract}
Background. Infections in critically ill patients are the main reasons for a lack of therapeutic success and increased mortality in intensive care units (ICUs). There have been many analyses of the incidence of infections in ICUs; however, no large studies of this kind have been conducted either in Poland or in Eastern and Central Europe.
\end{abstract}

Objectives. The aim of the research was to undertake a one-day study of the prevalence of infections in ICUs in Warszawa and the Mazovian region of Poland.

Material and methods. A prospective questionnaire survey analysis - a one-day prevalence study of infections - was carried out on June 25, 2014, in 28 ICUs in Poland.

Results. Among 205 ICU patients (193 adults and 12 children), 134 infections were found in 101 patients (99/193 adults (51.30\%) and 2/12 children (16.70\%)), and bacterial colonization in 19/205 (9.3\%) patients. In $66.42 \%$ of the cases, more than 1 site of infection was diagnosed. On the day of the study, $75.40 \%$ of the diagnosed infections had positive microbiological results. The most frequent were respiratory tract infections (53.73\%), wound infections (18.65\%) and bloodstream infections (14.92\%). Most of the infections (64.10\%) were caused by Gram-negative bacteria (GN), followed by Gram-positive bacteria (GP; 31.80\%) and fungi (4.10\%). The most frequently reported GN microorganisms were Enterobacteriaceae (44.7\%). Methicillinresistant Staphylococcus aureus (MRSA) infections were found in $8.80 \%$ of the patients. Antibiotics were administered to $75.60 \%$ of the adult patients, in $69.20 \%$ as targeted treatment. Mechanical ventilation, central vein catheterization and urinary bladder catheterization were used in $67.80 \%, 85.85 \%$ and $94.63 \%$ of the patients, respectively.

Conclusions. On the day of the study, more than half of the patients had infections, mostly from GN bacteria. Respiratory tract infections were the main type found. In about $2 / 3$ of the patients, antibiotics were administered, mainly as targeted therapy.

Key words: intensive care unit, hospital infection, one-day prevalence study 


\section{Introduction}

Infections in critically ill patients are the main reasons for a lack of therapeutic success and increased mortality in intensive care units (ICUs) all over the world. Unfortunately, the incidence of infections is still high. ${ }^{1-3}$ Many epidemiological studies have analyzed this problem, mainly in the populations of Western Europe, North America and developing countries. ${ }^{4-8}$ Among all these studies, one-day prevalence studies are favored because they can be carried out quickly and easily in different medical centers. The prototype for this type of analysis was the European Prevalence of Infection in Intensive Care (EPIC) Study. ${ }^{4}$ There have been no large studies of this type focused on ICU patients either in Poland or in Eastern and Central Europe. The objective of our research was a one-day study of the prevalence of infections in ICUs in Warszawa and the Mazovian region of Poland (about 7 million citizens).

\section{Material and methods}

\section{Study population and data collection}

Our study was a questionnaire-based survey analysis of the epidemiological status of critically ill patients who were hospitalized in ICUs on Tuesday, June 25, 2014. The study covered 205 patients in 28 ICUs in Poland. The study protocol was approved by the institutional Bioethics Committee and performed in accordance with the Declaration of Helsinki. We asked 15 questions about infections and pathogens "occurring in the ICU", and about all other aspects of therapy important to our analysis. The questionnaire was sent to 33 ICUs in 500- to 1000-bed university and municipal hospitals, as well as to smaller district hospitals (up to 250 beds). Two large pediatric hospitals (PD) were also included in our study. Of the 33 ICUs that received the questionnaire, 85\% completed the questionnaires and were included in the study. The patient characteristics are shown in Table 1.

Table 1. Patient characteristics

\begin{tabular}{|c|c|c|}
\hline \multicolumn{2}{|c|}{ Total number of patients } & 205 \\
\hline \multirow{2}{*}{ Gender } & male, n (\%) & $120(58.5)$ \\
\hline & female, n (\%) & $85(41.5)$ \\
\hline \multirow{2}{*}{$\begin{array}{l}\text { Type of medical } \\
\text { problem }\end{array}$} & general, n (\%) & $58(28.3)$ \\
\hline & surgical, n (\%) & $147(71.7)$ \\
\hline \multirow{2}{*}{ Age } & $>18$ years of age, $n(\%)$ & $193(94.1)$ \\
\hline & $<18$ years of age, $n(\%)$ & $12(5.9)$ \\
\hline \multicolumn{2}{|c|}{$\begin{array}{l}\text { ICU admission source: other departments of the same } \\
\text { hospital*, n (\%) }\end{array}$} & $143(69.8)$ \\
\hline \multicolumn{2}{|c|}{ Emergency departments* or other hospital, n (\%) } & $62(30.2)$ \\
\hline
\end{tabular}

Data is presented as number of patients and percentage value;

* data from departments for adult patients only.
We performed global epidemiological analyses in 28 ICUs (205 patients) as well as detailed analyses in Warszawa (WA - 11 hospitals), large Mazovian provincial hospitals (MPH - 5 hospitals) and district hospitals (DH - 12 hospitals). Additionally, we compared some results of our study to the European Prevalence of Infection in Intensive Care (EPIC) and EPIC II studies., ${ }^{4,5}$

\section{Definitions and diagnostic methods}

Infections were diagnosed based on the criteria of the Centres for Disease Control and Prevention's National Healthcare Safety Network (CDC/NHSN) and the European Centre for Disease Control (ECDC). ${ }^{9}$ All materials submitted for microbiological analysis were sampled and assessed qualitatively and quantitatively according to accepted standards. The susceptibility of microorganisms was determined in accordance with the recommendations of the European Committee on Antimicrobial Susceptibility Testing (EUCAST). ${ }^{10}$ Colonization was defined when microorganisms were found at a normally sterile site on the patient, without clinical or laboratory signs of infection. Patients were considered surgical if emergency surgery was performed immediately before admission or if elective surgery was performed within 1 month before admission. All other patients - e.g. with respiratory, cardiac or renal insufficiency - were considered medical. The incidence of infections was calculated as the number of patients with infections per 100 hospitalized patients.

\section{Statistical analysis}

The statistical analyses were performed using STATISTICA software v. 10 (StatSoft Inc., Tulsa, USA). Descriptive statistics were computed for all study variables. Discrete variables are expressed as counts (percentages) and mean \pm standard deviation (SD). The data was analyzed using the $X^{2}$ test or $X^{2}$ test with Yates's correction, as appropriate. P-value $<0.05$ was considered statistically significant.

\section{Results}

There were 238 intensive care beds for adults and 18 for children in the analyzed ICUs on the day of our study (WA - 135, MPH - 49, DH - 54). Among them, 193/238 intensive care beds (81.1\%) were occupied (WA - 90.4\%, $\mathrm{MPH}-73.5 \%$, DH - 64.8\%, PD - 66.7\%). Of the adult patients, $143 / 193(74.1 \%)$ were admitted to ICUs from other departments of the same hospital (WA - 84.4\%, $\mathrm{MPH}$ - 47.2\%, DH - 65.7\%), whereas 50/193 (25.9\%) were admitted from the emergency department or from other hospitals (WA - 16.4\%, MPH - 50\%, HD - 28.6\%). We do not have such data for 12 of the pediatric patients. 
Among the 205 patients hospitalized in an ICU, 134 infections were found. In total, 101 patients (49.26\%) - 99/193 adults (51.30\%; WA - 53.30\%, MPH - 47.20\%, DH - 51.40\%) and $2 / 12$ pediatric patients $(16.70 \%)$ - were considered infected. Of these, 101/134 infections (75.40\%) had positive microbiological results, whereas 33/134 (24.63\%) infections were diagnosed without positive microbiological results on the day of the study. Bacterial colonization was diagnosed in 18/193 of the adult cases (9.3\%; WA - 10.7\%, $\mathrm{MPH}-5.6 \%$, DH - 8.6\%). No bacterial colonization was diagnosed in the pediatric patients. Of the adult patients, 146/193 (75.6\%) received antimicrobial treatment. Among these patients, in $36.3 \%$ of the cases, 1 antimicrobial agent was administered, whereas 2 agents were administered in $45.9 \%, 3$ in $15.8 \%$, and 4 in $2.1 \%$. In $69.2 \%$ of the patients, there was targeted therapy, whereas in $22.6 \%$ and in $8.2 \%$, both empirical and prophylactic treatments were provided.
The prevalence of infections and primary sites of infections in the different types of hospital are shown in Table 2.

More than 1 site of infection was diagnosed in 89/134 cases (66.42\%; WA - 35.20\%, MPH - 38.80\%, DH - 17.10\%). The incidence of infections in ICUs for adults was 99/193 patients (51.30\%), mainly due to lung infections 70/193 (36.70\%). Respiratory tract infections were the most frequently found type of infections in adults (53.03\%), followed by bloodstream (15.50\%), urinary tract (12.88\%), abdominal (11.36\%), and wound infections (7.57\%).

The microorganisms responsible for infections in different types of hospitals are shown in Fig. 1. Among the isolated microorganisms ( $\mathrm{n}=170)$, the most common Gram-negative (GN) bacteria $(\mathrm{n}=109)$ were Klebsiella pneumoniae (32.9\%), Escherichia coli (20.0\%), Acinetobacter baumannii (5.3\%), Pseudomonas aeruginosa (4.1\%), and other microorganisms (1.8\%). Gram-positive (GP) bacteria

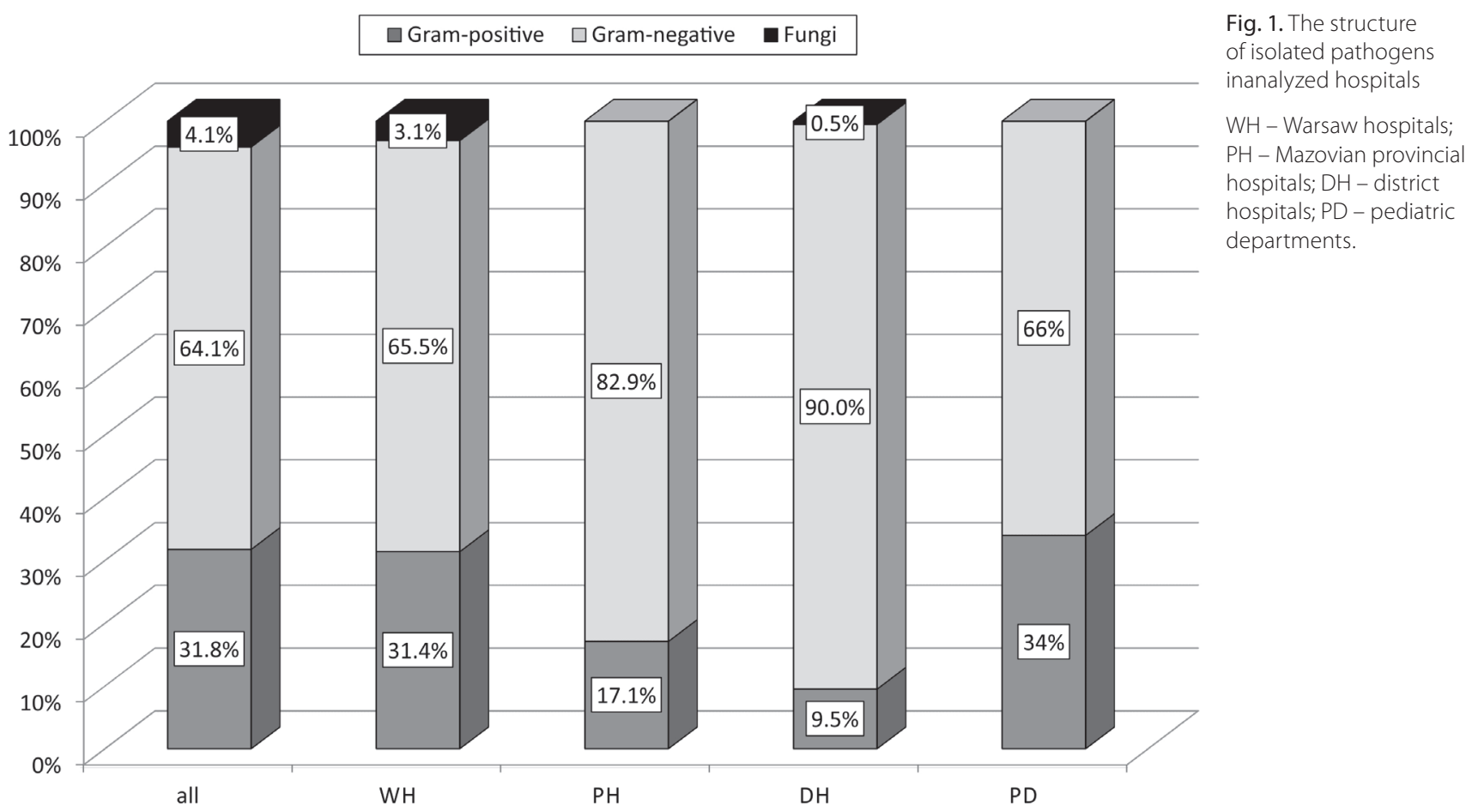

Table 2. Prevalence of infections in different types of hospitals

\begin{tabular}{|c|c|c|c|c|c|}
\hline Variables & WH & $\mathrm{MPH}$ & DH & PD & Total \\
\hline Total number of patients, $n$ & 122 & 36 & 35 & 12 & 205 \\
\hline Patients with no infections, n (\%) & \multicolumn{3}{|c|}{$94(48.7)$} & $10(83.3)$ & $104(50.7)$ \\
\hline Patients with infections, n (\%) & \multicolumn{3}{|c|}{$99(51.3)$} & $2(16.7)$ & $101(49.3)$ \\
\hline Total number of infections, n (\%) & $82(67.2)$ & $20(55.6)$ & $30(85.7)$ & $2(16.7)$ & $134(65.4)$ \\
\hline Lung infections, n (\%) & $43(35.2)$ & $9(25.0)$ & $18(51.4)$ & $2(16.7)$ & $72(35.1)$ \\
\hline Bloodstream infections, n (\%) & $11(9.0)$ & $7(19.4)$ & $2(5.7)$ & $0(0.0)$ & $20(9.8)$ \\
\hline Urinary tract infections, n (\%) & $12(9.8)$ & $4(11.1)$ & $1(2.9)$ & $0(0.0)$ & $17(8.3)$ \\
\hline Abdominal infections, $\mathrm{n}(\%)$ & $6(4.9)$ & $0(0.0)$ & $9(25.7)$ & $0(0.0)$ & $15(7.3)$ \\
\hline Wound infections n, (\%) & $10(8.2)$ & $0(0.0)$ & $0(0.0)$ & $0(0.0)$ & $10(4.9)$ \\
\hline
\end{tabular}

Data is presented as number of patients and percentage value. WH - Warsaw hospitals; MPH - Mazovian provincial hospitals; DH - district hospitals; PD - pediatric departments. 
Table 3. Device utilization ratios in different types of hospitals

\begin{tabular}{|c|c|c|c|c|c|}
\hline \multicolumn{2}{|c|}{ Variable } & WH & $\mathrm{MPH}$ & DH & $P D$ \\
\hline \multicolumn{2}{|c|}{ Total number of patients } & 122 & 36 & 35 & 12 \\
\hline \multirow{3}{*}{$\begin{array}{l}\text { Mechanical } \\
\text { ventilation }\end{array}$} & total & 87 (71.3\%) & $23(63.9 \%)$ & $20(57.1 \%)$ & $9(75.0 \%)$ \\
\hline & via endotracheal intubation & $66(75.9 \%)$ & $20(87.0 \%)$ & $17(85.0 \%)$ & $9(100.0 \%)$ \\
\hline & via tracheostomy & $21(24.1 \%)$ & $3(13.0 \%)$ & $3(15.0 \%)$ & $0(0.0 \%)$ \\
\hline \multicolumn{2}{|c|}{ Central vein catheter } & $116(95.1 \%)$ & $23(63.9 \%)$ & 29 (82.9\%) & $8(66.7 \%)$ \\
\hline \multicolumn{2}{|c|}{ Urinary catheter } & $120(98.4 \%)$ & $36(100.0 \%)$ & $33(94.3 \%)$ & $5(41.7 \%)$ \\
\hline
\end{tabular}

Data is presented as number of patients and percentage value. WH - Warsaw hospitals; MPH - Mazovian provincial hospitals; DH - district hospitals; PD - pediatric departments.

( $\mathrm{n}=54$ ) were Methicillin-resistant Staphylococcus epidermidis (MRSE; 10.6\%), Methicillin-resistant Staphylococcus aureus (MRSA; 10.0\%), Methicillin-susceptible Staphylococcus epidermidis (MSSE; 10.6\%), and Enterococcus spp. (5.9\%). The fungi found ( $\mathrm{n}=7$ ) were non-albicans Candida (100\%). The most frequently isolated pathogens responsible for pneumonia were $\mathrm{GN}$ bacteria (47/70, 67.1\%), mainly species of Enterobacteriaceae (21/47, 44.7\%) and non-fermenting GN strains such as A. baumannii (9/47, 19.1\%) and $P$. aeruginosa (7/47, 14.9\%). The GN pathogens $(5 / 47$, 10.6\%) (K. pneumoniae, $\mathrm{n}=3$; E. coli, $\mathrm{n}=1$; Enterobacter cloacae, $\mathrm{n}=1$ ) had extended-spectrum beta-lactamase (ESBL) mechanisms of bacterial resistance. Among the GP species (23/70, 32.9\%), S. aureus was the most frequently isolated (12/23, 54.0\%), specifically MRSA (8/12, 70.0\%).

The majority of bloodstream infections $(11 / 20,55 \%)$ were caused by GN bacteria (mainly Enterobacteriaceae), while $45 \%$ of the bloodstream infections were due to GP bacteria species, mainly Staphylococci $(\mathrm{n}=6)$ and Enterococci $(\mathrm{n}=3)$. Two cultures of vancomycin-resistant Enterococcus faecium were isolated.

The main pathogens responsible for urinary tract infections (UTI) were E. coli (12/17, 71.0\%), Enterococcus faecalis (3/17, 18.0\%) and other pathogens (2/17, 11.0\%). Methicillin-resistant Staphylococcus aureus infections were diagnosed in 17/193 patients (8.8\%). All A. baumannii strains found in this study were multi-drug resistant (MDR).

Non-albicans Candida infections were diagnosed in 7/193 patients (3.6\%; Candida glabrata $(\mathrm{n}=3)$, Candida kruzei $(\mathrm{n}=3)$, Candida tropicalis $(\mathrm{n}=1))$. Only 1 case of Clostridium difficile infection was diagnosed in this study.

Mechanical ventilation, central venous catheters and urinary catheters are considered risk factors for infections in critically ill patients. These factors are shown in Table 3.

\section{Discussion}

One-day point prevalence studies of infections in ICUs have been performed mainly in the USA, North European countries and Australia. ${ }^{4,5,11}$ Several such studies, carried out in ICUs or in all hospital departments, have focused on community-acquired infections (CAIs) and hospitalacquired infections (HAIs) or on HAIs only, although some of these studies also included analyses of the antimicrobials used. ${ }^{12-15}$ A one-day point prevalence study (PPS) and incidence study in Poland evaluated the epidemiology of infections in Polish long-term care facilities. ${ }^{16}$

The first Polish one-day PPS on infections in ICUs was performed in 59 ICUs in $1994 .{ }^{17}$ The most important differences in comparison to this study include the predomination of GP bacteria in the earlier study, which were isolated in $61.8 \%$ of the patients (of these, $67.0 \%$ were MRSA species). In our study, the percentage of GN bacteria was nearly double in comparison with the findings of the earlier Polish survey (35.2\%); Candida infections were also twice more prevalent (2.6\%). ${ }^{17}$

Because Poland lacks a history of one-day infection PPS performed in ICUs, we could compare our data only to the one-year prevalence study of Polish ICUs, which analyzed 1,043 critically ill patients with sepsis. ${ }^{18}$ In this earlier study, patients with GN bacterial sepsis were less frequent than in our study (48.0\% vs $64.1 \%$; P. aeruginosa $14.2 \%$ vs $4.1 \%$; A baumannii $15.3 \%$ vs $5.3 \%$ ). The main site of infection found in the previous study was the abdominal cavity (47.0\%), which is a contrast to the present study, where respiratory tract infections were predominant. ${ }^{18}$ In this regard, our findings were similar to the Sepsis Occurrence in Acutely Ill Patients (SOAP) study; other oneday PPSs also determined that the respiratory tract was the most common site of infection (68.0\%, 58.5\%, 28.0\%, and $20.0 \%$ according to Vincent et al., ${ }^{2}$ Toufen et al., ${ }^{13}$ Marioka et al., ${ }^{14}$ and Esen et al., ${ }^{15}$ respectively). ${ }^{2,13-15}$ However, in other studies (mainly analyzing HAIs), bloodstream infections were predominant. ${ }^{12,19}$

We analyzed data from 28 Polish ICUs, whereas the EPIC study analyzed data from 1,417 European ICUs; the EPIC II study analyzed data from 1,265 ICUs in North and South America, Western Europe, Asia, Oceania, Australia, and Africa. ${ }^{4,5}$ The incidence of infections in our study was comparable both to EPIC (44.80\%) and EPIC II (51.40\%). The incidence of lung infections in our study was also similar to EPIC II (36.30\% vs 32.60\%). Nevertheless, in our study, respiratory tract infections constituted $53.03 \%$ of all 
Table 4. Comparative analysis of point prevalence infection studies

\begin{tabular}{|c|c|c|c|c|}
\hline Variable & PPIC (adults) & $\mathrm{EPIC}^{4}$ & EPIC $\|^{5}$ & p-value \\
\hline Number of hospitalized patients & 193 & 10,038 & 13,796 & - \\
\hline Number of patients with infections & 99 & 4,501 & 7,087 & - \\
\hline $\begin{array}{l}\text { Total number of infections/total } \\
\text { number of hospitalized patients }\end{array}$ & $\begin{array}{l}132 / 193 \\
(68.39 \%)\end{array}$ & $\begin{array}{l}4,501 / 10,038 \\
(44.8 \%)\end{array}$ & $\begin{array}{l}7,087 / 13,796 \\
(51.4 \%)\end{array}$ & $\begin{array}{l}p=0.0000 \\
p^{*}=0.0000\end{array}$ \\
\hline \multirow{2}{*}{$\begin{array}{l}\text { Respiratory tract infections } \\
\text { including pneumonia }\end{array}$} & $\begin{array}{c}70 / 193 \\
(36.27 \%)\end{array}$ & $\begin{array}{l}967 / 10038 \\
(9.63 \%)\end{array}$ & $\begin{array}{l}4,503 / 13,796 \\
(32.64 \%)\end{array}$ & $\begin{array}{l}p=0.0000 \\
p^{*}=0.983\end{array}$ \\
\hline & $\begin{array}{c}70 / 132 \\
(53.03 \%)\end{array}$ & $\begin{array}{l}967 / 4501 \\
(21.48 \%)\end{array}$ & $\begin{array}{l}4,503 / 7,087 \\
(63.5 \%)\end{array}$ & $\begin{array}{l}p=0.0000 \\
p^{*}=0.2858\end{array}$ \\
\hline \multirow{2}{*}{ Bloodstream infections } & $\begin{array}{c}20 / 193 \\
(10.36 \%)\end{array}$ & $\begin{array}{c}247 / 10,038 \\
(2.46 \%)\end{array}$ & $\begin{array}{c}1,071 / 13,796 \\
(7.76 \%)\end{array}$ & $\begin{array}{l}p=0.0000 \\
p^{*}=0.1811\end{array}$ \\
\hline & $\begin{array}{l}20 / 132 \\
(15.15 \%)\end{array}$ & $\begin{array}{c}247 / 4,501 \\
(5.49 \%)\end{array}$ & $\begin{array}{c}1,071 / 7,087 \\
(15.1 \%)\end{array}$ & $\begin{array}{l}p=0.0000 \\
p^{*}=0.9900\end{array}$ \\
\hline \multirow{2}{*}{ Urinary tract infections } & $\begin{array}{l}17 / 193 \\
(8.81 \%)\end{array}$ & $\begin{array}{c}363 / 10,038 \\
(3.62 \%)\end{array}$ & $\begin{array}{l}1,011 / 13,796 \\
(7.33 \%)\end{array}$ & $\begin{array}{l}p=0.0002 \\
p^{*}=0.4339\end{array}$ \\
\hline & $\begin{array}{c}17 / 132 \\
(12.88 \%)\end{array}$ & $\begin{array}{c}363 / 4,501 \\
(8.06 \%)\end{array}$ & $\begin{array}{c}1,011 / 7,087 \\
(14 \%)\end{array}$ & $\begin{array}{l}p=0.0470 \\
p^{*}=0.6515\end{array}$ \\
\hline Patients receiving antibiotics & $\begin{array}{l}146 / 193 \\
(75.6 \%)\end{array}$ & $\begin{array}{c}6,250 / 10,038 \\
(62.3 \%)\end{array}$ & $\begin{array}{c}9,084 / 13,796 \\
(71 \%)\end{array}$ & $\begin{array}{c}p=0.0001 \\
p^{*}=0.0043\end{array}$ \\
\hline
\end{tabular}

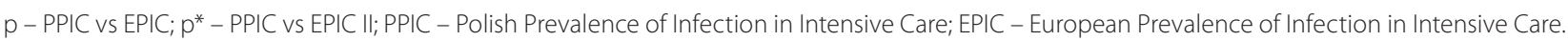

infections, in comparison to $63.50 \%$ in EPIC II. The incidence of blood infections in our study was also similar to the EPIC II study (10.40\% vs $7.80 \%)$, as was the incidence of UTIs $(8.80 \%$ vs $7.30 \%)$. We did not find any difference in the incidences of respiratory tract infections and bloodstream infections when we compared our study to the EPIC study. The incidence of UTIs in our study was higher than in the EPIC study (8.80\% vs 3.62\%). ${ }^{4,5}$ A comparative analysis of these 3 PPSs is shown in Table 4.

Data from the European Centre for Disease Control and Prevention point prevalence survey showed that the prevalence of HAIs in pediatric ICUs was $15.5 \% .{ }^{19}$ That was supported by our observations; nevertheless, our study showed lung infections as the most common, while in the ECDC point prevalence survey, bloodstream infections were the most common type of infection (45.0\%). ${ }^{19}$ The EPIC and EPIC II studies reported the incidence of infections caused by GN bacteria as $32.0 \%$ and $62.0 \%$, respectively. ${ }^{4,5}$ Only the EPIC II microbiological results were consistent with our findings, in which GN bacterial infections were predominant. The main GN pathogens in our study were members of the Enterobacteriaceae family. This is similar to other studies, such as those from Brazil (33.8\%) and Japan (27.6\%). ${ }^{13,14}$

A high number of infections caused by $A$. baumannii, as well as resistance to many groups of antibiotics among GN bacteria, was noted in studies by Weiner et al. ${ }^{20}$ and Harris et al. ${ }^{21}$ We did not observe this phenomenon in our study. The relatively small number of $A$. baumannii infections in our observations may result from sample size; Weiner et al. analyzed information from 4,515 hospitals. Moreover, our data was collected more than 3 years ago, when the number of such infections was lower in comparison to the present day. In addition, the number of infections caused by A. baumannii may be a picture of the epidemiological situation only on the particular day the study was performed.

The frequency of MRSA infections was lower in our study in comparison to the results of one-day multicenter PPS from Turkey (18.20\%) and Brazil (16.90\%) as well as the EPIC study (20.00\%), and was similar to the frequency observed in EPIC II (10.20\%). ${ }^{4,5,13,15}$ We found no infections caused by colistin-resistant $A$. baumannii, although the literature includes data on $A$. baumannii resistance to colistin amounting to $2.95 \% .^{22}$ The low percentage of infections caused by GN pathogens that produce ESBL in our study was similar to the observations of Coque et al. ${ }^{23}$ The rate of $C$. difficile infections (only 1 isolated pathogen) was lower in our study than in Bartlett's work. ${ }^{24}$ This may result from the methodology of our study. We decided to analyze only $C$. difficile infections confirmed with microbiological tests. Moreover, according to data of Kübler et al., ${ }^{18}$ metronidazole is administered to septic patients in Polish ICUs very often because about half of the infections in the critically ill originate in the abdominal cavity. Metronidazole is effective against $C$. difficile, so it may be the reason such infections were not noted in this oneday study.

In summary, the most effective way to control infection problems in ICUs is to strictly follow antiseptic rules (hand hygiene, the use of alcohol-based hand rub solution and HAI monitoring) and to assess compliance with protocols related to these infections that are being implemented in Polish hospitals. ${ }^{6,25,26}$

Our study had several limitations. First, the analysis could have been affected by the respondents' level 
of carefulness in completing the questionnaires. Second, our study included multiple hospitals, but the ICUs were situated within 1 geographic area, and the epidemiology of infections in the rest of Poland may not be the same. Third, it is quite noticeable that the data on pediatric patients is rather small: there were 12 patients, and only 2 of them had infections. This is not a representative sample, and all the comparisons involving this group should be considered very cautiously. Fourth, preventive methods could have influenced the rate and epidemiology of HAIs, and this factor was not analyzed. Fifth, we did not precisely analyze the origin of infections, so some could be community-acquired and some hospital-acquired. Also, the use of medical devices may promote infections in hospitalized patients. However, because of the methodology of the study and the nature of the data received, it was not possible to perform analyses that would take these factors into account. Sixth, we did not analyze survival because we completed our observations within $24 \mathrm{~h}$. Finally, some limitations resulted from the methodology of the study; nevertheless, the small number of published studies with the same methodology indicates that there is limited research in this field and shows that our analysis is very important for this part of Europe.

\section{References}

1. Angus DC, Linde-Zwirble WT, Lidicker J, Clermont G, Carcillo J, Pinsky MR. Epidemiology of severe sepsis in the United States: Analysis of incidence, outcome, and associated costs of care. Crit Care Med. 2001;29(7):1303-1310.

2. Vincent JL, Sakr Y, Sprung CL, et al; Sepsis Occurrence in Acutely III Patients Investigators. Sepsis in European intensive care units: Results of the SOAP study. Crit Care Med. 2006;34(2):344-353.

3. Esteban A, Frutos-Vivar F, Ferguson ND, et al. Sepsis incidence and outcome: Contrasting the intensive care unit with the hospital ward. Crit Care Med. 2007;35(5):1284-1289.

4. Vincent $J \mathrm{~L}$, Bihari DJ, Suter PM, et al. The prevalence of nosocomial infection in intensive care units in Europe. Results of the European Prevalence of Infection in Intensive Care (EPIC) Study. EPIC International Advisory Committee. JAMA. 1995;274(8):639-644.

5. Vincent JL, Rello J, Marshall J, et al; EPIC II Group of Investigators. International study of the prevalence and outcomes of infection in intensive care units. JAMA. 2009;302(21):2323-2329.

6. Rosenthal VD, Al-Abdely HM, El-Kholy AA, et al. International Nosocomial Infection Control Consortium report, data summary of 50 countries for 2010-2015: Device-associated module. Am J Infect Control. 2016;44(12):1495-1504.

7. Dudeck MA, Weiner LM, Allen-Bridson K, et al. National Healthcare Safety Network (NHSN) report, data summary for 2012, device-associated module. Am J Infect Control. 2013;41(12):1148-1166.

8. European Centre for Disease Prevention and Control. Annual Epidemiological Report 2016 - Healthcare-associated infections acquired in intensive care units. (online) 2016. http://ecdc.europa.eu/en/ healthtopics/Healthcare-associated_infections/ICU-acquired-infections/Pages/Annual-epidemiological-report-2016. Accessed September 30, 2017.
9. Horan TC, Andrus M, Dudeck MA. CDC/NHSN surveillance definition of health care-associated infection and criteria for specific types of infections in the acute care setting. Am J Infect Control. 2008;36(5): 309-332.

10. European Committee on Antimicrobial Susceptibility Testing (EUCAST). Breakpoint tables for interpretation of MICs and zone diameters. Version 6.0.; 2016. http://www.eucast.org/clinical_breakpoints/. Accessed September 30, 2017.

11. Magill SS, Edwards JR, Bamberg W, et al; Emerging Infections Program Healthcare-Associated Infections and Antimicrobial Use Prevalence Survey Team. Multistate point-prevalence survey of health care-associated infections. N Engl J Med. 2014;370(13):1198-1208.

12. Balkhy HH, Cunningham G, Chew FK, et al. Hospital- and community-acquired infections: A point prevalence and risk factors survey in a tertiary care center in Saudi Arabia. Int J Infect Dis. 2006;10(4): 326-333.

13. Toufen Junior C, Hovnanian AL, Franca SA, Carvalho CR. Prevalence rates of infection in intensive care units of a tertiary teaching hospital. Rev Hosp Clin Fac Med Sao Paulo. 2003;58(5):254-259.

14. Morioka $H$, Hirabayashi $A$, Iguchi $M$, et al. The first point prevalence survey of health care-associated infection and antimicrobial use in a Japanese university hospital: A pilot study. Am J Infect Control. 2016;44(7):e119-e123.

15. Esen S, Leblebicioglu H. Prevalence of nosocomial infections at intensive care units in Turkey: A multicentre 1-day point prevalence study. Scand J Infect Dis. 2004;36(2):144-148.

16. Wójkowska-Mach J, Gryglewska B, Czekaj J, Adamski P, Grodzicki T, Heczko PB. Infection control: Point prevalence study versus incidence study in Polish long-term care facilities in 2009-2010 in the Małopolska Region. Infection. 2013;41(1):1-8.

17. Rybicki Z, Truszczyński A, Kowalczyk W, Goraj R. Analysis of bacteria population and sensitivity to antibiotic therapy in intensive care unit patients. One-day trial. Clin Microbiol Infect. 1997;3:P336.

18. Kübler A, Durek G, Zamirowska A, et al. Severe sepsis in Poland: Results of internet surveillance of 1043 cases. Med Sci Monit. 2004; 10(11):CR635-CR641.

19. Zingg W, Hopkins S, Gayet-Ageron A, et al; ECDC PPS study group. Health-care-associated infections in neonates, children, and adolescents: An analysis of paediatric data from the European Centre for Disease Prevention and Control point-prevalence survey. Lancet Infect Dis. 2017;17(4):381-389.

20. Weiner LM, Webb AK, Limbago B, et al. Antimicrobial-resistant pathogens associated with healthcare-associated infections: Summary of data reported to the National Healthcare Safety Network at the Centers for Disease Control and Prevention, 2011-2014. Infect Control Hosp Epidemiol. 2016;37(11):1288-1301.

21. Harris KI, Perencevich EN, Rosenthal GE, Herwaldt LA. Multidrugresistant Acinetobacter baumannii: A growing worldwide problem. Infect Dis Clin Pract (Baltim Md). 2013;21:285-288.

22. Maraki S, Mantadakis E, Mavromanolaki VE, Kofteridis DP, Samonis G. A 5-year surveillance study on antimicrobial resistance of Acinetobacter baumannii clinical isolates from a tertiary Greek hospital. Infect Chemother. 2016;48(3):190-198.

23. Coque TM, Baquero F, Canton R. Increasing prevalence of ESBL-producing Enterobacteriaceae in Europe. Euro Surveill. 2008;13(47). pii: 19044.

24. Bartlett JG. Clinical practice. Antibiotic-associated diarrhea. N Engl J Med. 2002;346(5):334-339.

25. Duszyńska W, Rosenthal VD, Dragan B, et al. Ventilator-associated pneumonia monitoring according to the INICC project at one centre. Anaesthesiol Intensive Ther. 2015;47(1):34-39.

26. Duszyńska W, Rosenthal VD, Szczęsny A, et al. Urinary tract infections in intensive care unit patients: A single-centre, 3-year observational study according to the INICC project. Anaesthesiol Intensive Ther. 2016;48(1):1-6. 